\title{
Comparison of the Variability of SUV Normalized by Skeletal Volume with the Variability of SUV Normalized by Body Weight in ${ }^{18}$ F-Fluoride PET/CT
}

\author{
José Flávio Gomes Marin ${ }^{1}$, Paulo Schiavom Duarte ${ }^{1}$, José Willegaignon de Amorim de Carvalho ${ }^{1}$, Heitor Naoki Sado ${ }^{1}$, \\ Marcelo Tatit Sapienza ${ }^{2}$, and Carlos Alberto Buchpiguel ${ }^{1,2}$ \\ ${ }^{1}$ Division of Nuclear Medicine, São Paulo Cancer Institute, São Paulo, Brazil; and ${ }^{2}$ University of São Paulo Medical School, São \\ Paulo, Brazil
}

Our objective was to test the hypothesis that variability in SUV normalized by skeletal volume (SV) in ${ }^{18} \mathrm{~F}$-fluoride $\left({ }^{18} \mathrm{~F}-\mathrm{NaF}\right)$ PET/CT studies is lower than variability in SUV normalized by body weight (BW). Methods: The mean SUV (SUV mean $)$ was obtained for whole skeletal volume of interest (wsVOI) in 163 selected ${ }^{18} \mathrm{~F}-\mathrm{NaF}$ PET/CT studies. These studies were performed to investigate bone metastases and were considered to have normal results. SUV mean was calculated with normalization by BW (BW SUV mean $_{\text {), with normalization by SV (SV SUV }}$ mean), and without normalization (WN SUV mean $)$. The total SV for each patient was also estimated on the basis of the wsVOI defined on the CT component of the PET/CT study. SUV $V_{\text {mean }}$ variability for each patient was estimated as the absolute value of the difference between the SUV mean for the patient and the mean of the SUV $\mathrm{S}_{\text {mean }}$ for the whole group of patients, divided by the mean of the SUV $\mathrm{S}_{\text {mean }}$ for the whole group of patients. The variabilities of $\mathrm{SUV}_{\text {mean }}$ calculated by the 3 methods were compared using a paired 1-tailed Wilcoxon test. Results: The mean variability for the BW, SV, and WN SUV mean was $0.16,0.13$, and 0.16 , respectively. There were statistically significant differences between SV and BW SUV mean $_{\text {variability }}(P=0.03)$ and between SV and WN $\mathrm{SUV}_{\text {mean }}$ variability $(P<0.01)$. There was no statistically significant difference between BW and WN SUV mean variability $(P=0.4)$. Conclusion: In patients with normal ${ }^{18} \mathrm{~F}-\mathrm{NaF}$ PET/CT results, SV SUV $_{\text {mean }}$ presents lower variability than BW SUV mean.

Key Words: ${ }^{18} \mathrm{~F}-\mathrm{NaF} ;{ }^{18} \mathrm{~F}$-fluoride; PET/CT; SUV; normalization J Nucl Med Technol 2019; 47:60-63

DOI: 10.2967/jnmt.118.215111

$\mathbf{T}$ he SUV is often used in PET imaging for semiquantitative analysis (1). SUV is defined as the tissue concentration of tracer as measured by a PET scanner, divided by the activity injected per unit volume of distribution, frequently the body weight (BW) (2).

\footnotetext{
Received May 25, 2018; revision accepted Aug. 6, 2018.

For correspondence or reprints contact: Paulo Schiavom Duarte, Division of Nuclear Medicine ( $4^{\circ} \mathrm{SS}$ ), São Paulo Cancer Institute, 251 Doctor Arnaldo Ave., Consolação, São Paulo/SP 01246-000, Brazil.

E-mail: psduarte@hotmail.com

Published online Aug. 23, 2018.

COPYRIGHT (c) 2019 by the Society of Nuclear Medicine and Molecular Imaging.
}

Although SUV has been used predominantly for ${ }^{18} \mathrm{~F}-\mathrm{FDG}$ PET/CT imaging quantification, it can also be used with other PET tracers. The use of SUV in ${ }^{18} \mathrm{~F}$-fluoride $\left({ }^{18} \mathrm{~F}-\mathrm{NaF}\right)$ PET/ CT studies has been described $(3,4)$. There are reports demonstrating that SUV can detect significant metabolic alterations in individual metastatic lesions on ${ }^{18} \mathrm{~F}-\mathrm{NaF}$ PET/CT images, even when visual evaluation reveals little, if any, difference (5). Moreover, SUV measurement may provide additional information in assessing treatment response using ${ }^{18} \mathrm{~F}-\mathrm{NaF}$ PET/CT studies $(5,6)$.

However, to properly use SUV in clinical practice, it is important to be aware of factors that can alter these values. For calculating SUV in ${ }^{18} \mathrm{~F}-\mathrm{FDG}$ PET/CT studies, some authors prefer to use lean body mass (7) or body surface area (8) as a measure of the distribution of the radiopharmaceutical, instead of the more frequently used BW. Zasadny and Wahl (7) stated that if there is no significant uptake of ${ }^{18} \mathrm{~F}-\mathrm{FDG}$ in fat tissue, lean body mass instead of total BW should be used as a measure of the volume of radiopharmaceutical distribution. There are articles proposing that lean body mass SUV is independent of BW $(7,9)$, and this methodology has also been advocated as preferable for quantifying metabolic activity when assessing treatment response in clinical trials (10). There are also articles discussing the best methods to estimate lean body mass in ${ }^{18} \mathrm{~F}-\mathrm{FDG}$ PET/CT studies. Although predictive equations are adequate for lean body mass estimation (11), methods based on CT images are more accurate $(12,13)$.

Because ${ }^{18} \mathrm{~F}-\mathrm{NaF}$ has a nonhomogeneous distribution in the body, with predominant bone uptake and minimal softtissue uptake, we hypothesized that SUV normalization by skeletal volume (SV) may be more appropriate than normalization by BW for this radiopharmaceutical and may provide less variable results.

Our objective was to test the hypothesis that in ${ }^{18} \mathrm{~F}-\mathrm{NaF}$ studies, variability is lower for SUV normalized by SV than for SUV normalized by BW.

\section{MATERIALS AND METHODS \\ Patient Population \\ The institutional review board approved this retrospective study, and the requirement to obtain informed consent was waived.}


We analyzed ${ }^{18} \mathrm{~F}-\mathrm{NaF}$ PET/CT studies performed on 163 patients. These studies were retrospectively selected from a database of more than $2,000{ }^{18} \mathrm{~F}-\mathrm{NaF}$ PET/CT studies performed in our institution to investigate bone metastasis in patients with oncologic diseases. The selection criterion was visually normal or near-normal radiopharmaceutical uptake in the skeleton on PET and CT images. Patients with chronic renal failure were also excluded. The patient characteristics are presented in Table 1.

\section{PET/CT Image Acquisition}

The patients were injected with around $185 \mathrm{MBq}$ of ${ }^{18} \mathrm{~F}-\mathrm{NaF}$ and, about $60 \mathrm{~min}$ afterward, underwent whole-body (vertex to toes) 3-dimensional PET/CT. Images were acquired on a Discovery 690 time-of-flight PET/CT scanner (GE Healthcare) with a 64slice CT component. Emission PET images were obtained at $1 \mathrm{~min}$ per bed position (15-cm axial field of view with $3 \mathrm{~cm}$ of overlap), with $13-15$ bed positions per study. CT transmission scans (30 $\mathrm{mAs}$ ) were obtained for attenuation correction. Other CT acquisition parameters were $120 \mathrm{kVp}, 0.5$-s rotation time, 1.375 pitch, and 3.75-mm axial slice thickness. PET images were reconstructed using ordered-subsets expectation maximization with 2 iterations and 24 subsets. CT image reconstruction was based on conventional filtered backprojection with the GE Healthcare Bone Plus filter.

\section{Image Analysis}

$\mathrm{SUV}_{\text {mean }}$ normalized by BW (BW $\mathrm{SUV}_{\text {mean }}$ ) was obtained in whole skeletal volume of interest (wsVOI) for the 163 selected ${ }^{18} \mathrm{~F}-\mathrm{NaF}$ PET/CT studies. The wsVOI was automatically defined on the CT component of the PET/CT studies, using AMIDE software (14). A threshold of $120 \mathrm{HU}$ was used to separate bone from soft tissues. The BW $\mathrm{SUV}_{\text {mean }}$ in the wsVOI was automatically calculated by the software. The total SV for each patient was also automatically estimated by the software based on the whole SV of interest (Table 1). Therefore, the wsVOI was used to estimate the $\mathrm{BW} \mathrm{SUV} \mathrm{V}_{\text {mean }}$ in the whole skeleton and the total volume of the skeleton. An example of a wsVOI is presented in Figure 1.

$\mathrm{SUV}_{\text {mean }}$ normalized by SV (SV SUV $\mathrm{Sean}_{\text {m }}$ ) for each patient was

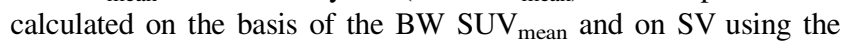
following equation:

$\mathrm{SVSUV}_{\text {mean }}=(\mathrm{BW} \mathrm{SUV}$ mean $/$ patient weight $) \times$ patient $\mathrm{SV}$.

Eq. 1

TABLE 1

Characteristics of Patients

\begin{tabular}{|c|c|}
\hline Characteristic & Data \\
\hline \multicolumn{2}{|l|}{$\operatorname{Sex}(n)$} \\
\hline $\begin{array}{l}\text { Female } \\
\text { Male }\end{array}$ & $\begin{array}{r}131(80.37 \%) \\
32(19.63 \%)\end{array}$ \\
\hline \multicolumn{2}{|l|}{ Age (y) } \\
\hline $\begin{array}{l}\text { Mean } \pm \text { SD } \\
\text { Range }\end{array}$ & $\begin{array}{c}52.66 \pm 13.18 \\
91.09-24.05\end{array}$ \\
\hline \multicolumn{2}{|l|}{ Creatinine (mg/dL) } \\
\hline $\begin{array}{l}\text { Mean } \pm \text { SD } \\
\text { Range }\end{array}$ & $\begin{array}{c}0.75 \pm 0.19 \\
1.53-0.28\end{array}$ \\
\hline \multicolumn{2}{|l|}{ Weight (kg) } \\
\hline $\begin{array}{l}\text { Mean } \pm \text { SD } \\
\text { Range }\end{array}$ & $\begin{array}{l}67.07 \pm 12.31 \\
108.00-39.00\end{array}$ \\
\hline \multicolumn{2}{|l|}{ SV (L) } \\
\hline $\begin{array}{l}\text { Mean } \pm \text { SD } \\
\text { Range }\end{array}$ & $\begin{array}{c}5.72 \pm 0.86 \\
8.76-3.57\end{array}$ \\
\hline
\end{tabular}

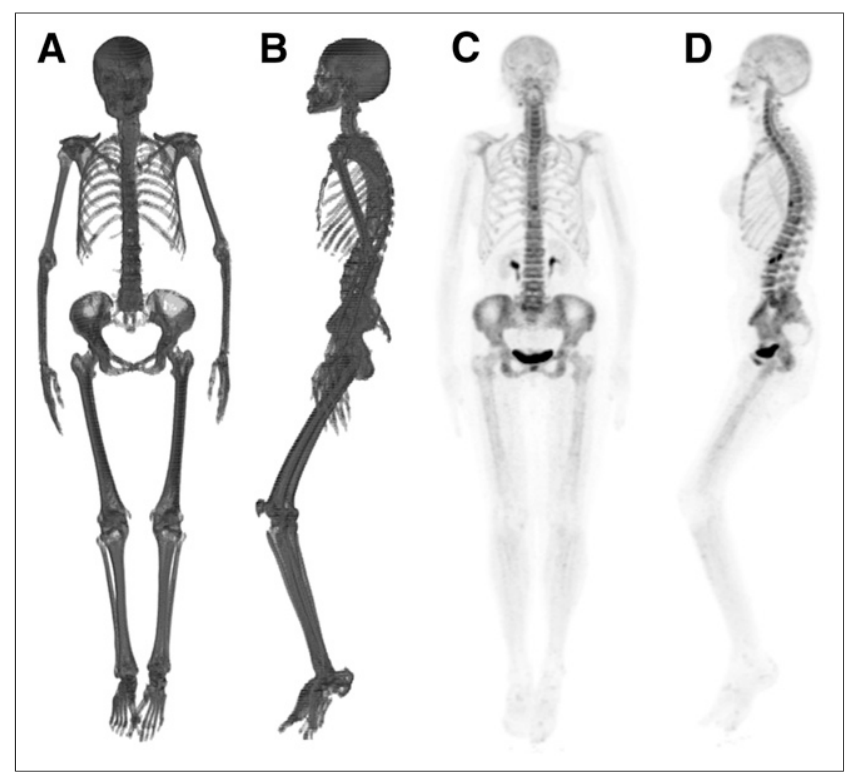

FIGURE 1. Coronal (A) and sagittal (B) 3-dimensional volumerendered projections of wsVOI and corresponding coronal (C) and sagittal (D) maximum-intensity projections of near-normal

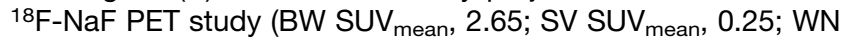
SUV $_{\text {mean }}, 0.05$; SV, 5.3 L).

The $\mathrm{SUV}_{\text {mean }}$ without normalization (WN $\mathrm{SUV}_{\text {mean }}$ ) was also calculated. This calculation was performed to assess whether the 2 analyzed normalization methods (BW and SV) have any impact on the variability in $\mathrm{SUV}_{\text {mean }}$ when compared with $\mathrm{SUV}_{\text {mean }}$ calculated without normalization (WN).

$\mathrm{WN} \mathrm{SUV}_{\text {mean }}$ for the whole skeleton was calculated using the following equation:

$$
\mathrm{WNSUV}_{\text {mean }}=\mathrm{BW} \mathrm{SUV}_{\text {mean }} / \text { patient weight. } \quad \text { Eq. } 2
$$

\section{Statistical Analysis}

The variability in whole-skeleton $\mathrm{SUV}_{\text {mean }}$ is defined as follows:

Variability for each patient

$=\operatorname{ABS}\left(\left[\mathrm{SUV}_{\text {mean }}-\right.\right.$ mean $\mathrm{SUV}_{\text {mean }} /$ mean $\left.\left.\mathrm{SUV}_{\text {mean }}\right]\right), \quad$ Eq. 3

where ABS is absolute value of SUV variability for each patient, $\mathrm{SUV}_{\text {mean }}$ is the mean SUV in the wsVOI for each patient, and the mean $\mathrm{SUV}_{\text {mean }}$ is the mean value of $\mathrm{SUV}_{\text {mean }}$ for the whole group of patients.

The means, SD, and maximal values of variability obtained using the 3 SUV normalization methodologies were calculated and then compared using a paired 1-tailed Wilcoxon test.

Statistical analysis was performed using Excel 2007 (Microsoft Inc.) and SPSS statistics 20 (IBM Corp.).

\section{RESULTS}

The means, SD, minimum, and maximum values of the $\mathrm{SUV}_{\text {mean }}$ normalized by the 3 methodologies are presented in Table 2. 
TABLE 2

Whole-Skeleton SUV mean Normalized by BW, SV, and WN for 163 Studies Analyzed

\begin{tabular}{|c|c|c|c|c|}
\hline $\begin{array}{l}\text { Whole-skeleton } \\
\text { SUV }_{\text {mean }} \text { parameter }\end{array}$ & Mean & SD & Maximum & Minimum \\
\hline BW SUV $V_{\text {mean }}$ & 2.60 & 0.52 & 4.22 & 1.5 \\
\hline $\begin{array}{l}\text { SV SUV } \\
\text { WN SUV }_{\text {mean }}\end{array}$ & $\begin{array}{l}0.22 \\
0.04\end{array}$ & $\begin{array}{l}0.04 \\
0.01\end{array}$ & $\begin{array}{l}0.33 \\
0.07\end{array}$ & $\begin{array}{l}0.12 \\
0.02\end{array}$ \\
\hline BW SUV $_{\text {mean }}$ variability & 0.16 & 0.12 & 0.62 & 0.00 \\
\hline $\begin{array}{l}\text { SV SUV } \\
\text { WN SU variability } \\
\text { WN } \\
\text { variability }\end{array}$ & $\begin{array}{l}0.13 \\
0.16\end{array}$ & $\begin{array}{l}0.10 \\
0.12\end{array}$ & $\begin{array}{l}0.47 \\
0.67\end{array}$ & $\begin{array}{l}0.00 \\
0.00\end{array}$ \\
\hline
\end{tabular}

The means, SD, minimum, and maximum values of variability obtained using the 3 methodologies are also presented in Table 2 . The mean variability for BW, SV, and $\mathrm{WN} \mathrm{SUV}_{\text {mean }}$ was $0.16,0.13$, and 0.16 , respectively (Table 2). The maximum variability for BW, SV, and $\mathrm{WN} \mathrm{SUV}_{\text {mean }}$ was $0.62,0.47$, and 0.67 , respectively (Table 2 ).

The paired 1-tailed Wilcoxon test showed statistically significant differences between the variabilities of SV and BW $\operatorname{SUV}_{\text {mean }}(P=0.03)$ and between the variabilities of $\mathrm{SV}$ and WN SUV $\mathrm{Wean}(P<0.01)$. There was no statistically significant difference between the variabilities of BW and $\mathrm{WN}$ $\operatorname{SUV}_{\text {mean }}(P=0.4)$.

\section{DISCUSSION}

In the last few years, there has been a renewed clinical interest in the use of ${ }^{18} \mathrm{~F}-\mathrm{NaF}$ as a bone scanning agent (15). Reasons for this resurgence include periodic worldwide shortages of ${ }^{99 \mathrm{~m}} \mathrm{Tc}$, which is needed to label radiopharmaceuticals for bone scanning (16), and the improved sensitivity $(17-19)$ and quantitative potential $(5,6)$ of ${ }^{18} \mathrm{~F}-\mathrm{NaF}$ PET/CT over technetium-based conventional bone scans.

Despite this quantitative potential, the main form of analysis for ${ }^{18} \mathrm{~F}-\mathrm{NaF}$ PET/CT studies has been visual interpretation. However, the scientific literature shows that SUV could be useful in some situations. Kubota et al. (20) investigated the usefulness of ${ }^{18} \mathrm{~F}-\mathrm{NaF}$ PET as a predictor of femoral head collapse in patients with osteonecrosis before radiographic changes occur. They concluded that quantitative assessment of $\mathrm{SUV}_{\max }$ in ${ }^{18} \mathrm{~F}-\mathrm{NaF}$ PET was useful in predicting collapse. Waterval et al. (21) assessed uptake of ${ }^{18} \mathrm{~F}-\mathrm{NaF}$ in patients with otosclerosis and evaluated its use as a complementary diagnostic tool. They concluded that ${ }^{18} \mathrm{~F}-\mathrm{NaF}$ PET using SUV measurements has the potential to be a diagnostic tool in otosclerosis. Cook et al. (5) evaluated the use of ${ }^{18} \mathrm{~F}-\mathrm{NaF}$ PET with SUV analysis as an alternative biomarker of bone metastasis response to ${ }^{223} \mathrm{Ra}$-chloride treatment. They concluded that SUV is more accurate than qualitative comparison of scans in assessing response. In more recent papers, techniques to measure the burden of bone disease have been demonstrated (22), and such measurements have been associated with prognosis (23). In those articles, the volumes of interest were based on metabolic uptake and SUV thresholds. Therefore, the adequate use of SUV is fundamental in some clinical situations. However, to properly use SUV in clinical practice, it is important to establish factors that can impact the values.

In the present article, we proposed a technique to normalize SUVs by SV instead of by BW when evaluating ${ }^{18} \mathrm{~F}-\mathrm{NaF}$ PET bone images. In this technique, the $\mathrm{SV}$ is based on bone boundaries defined on the CT component of the PET/CT study using AMIDE software, a free tool for analyzing medical imaging (14). The rationale behind this normalization is the high specific uptake of ${ }^{18} \mathrm{~F}-\mathrm{NaF}$ by bone and the minimal uptake by soft tissues. Our analyses demonstrated that whole-skeleton $\mathrm{BW} \mathrm{SUV}_{\text {mean }}$ is more variable than whole-skeleton SV SUV mean. This phenomenon could be explained by the fact that when SUV is measured in a wsVOI and normalized by BW, the numerator of the ratio will be similar in patients with similar bone metabolism. However, if patients have an extremely high or low weight, the denominator will be lower in patients with higher weight, increasing the SUV results, and higher in patients with lower weight, decreasing the SUV results. On the other hand, for SV SUV ${ }_{\text {mean }}$, the denominator will not change expressively with the variation in bone volume, and if it changes, this variation should also be reflected in the numerator value, since distribution of the radiopharmaceutical is the same in both. The results also demonstrated that the variability in $\mathrm{BW} \mathrm{SUV}$ mean is similar to that in $\mathrm{WN} \mathrm{SUV}_{\text {mean }}$, as corroborates the hypothesis that normalization by $\mathrm{BW}$ is not an adequate methodology in ${ }^{18} \mathrm{~F}-\mathrm{NaF}$ PET/CT studies.

The use of routinely collected CT data from PET/CT studies to estimate body tissue composition, and the application of that information to normalize SUV, is not a new idea. Hamill et al. (24) proposed models to estimate lean mass from CT HUs and used that to normalize SUV in ${ }^{18} \mathrm{~F}-\mathrm{FDG}$ PET/CT studies. They concluded that the methods based on CT were less variable than the $\mathrm{BW}$ method and were comparable to the lean body mass method calculated using an empiric formula. Kim et al. (25) compared SUV normalized by lean body mass as determined by CT in ${ }^{18} \mathrm{~F}-\mathrm{FDG}$ PET/CT with SUV determined by predictive equations. They concluded that normalization of SUV by lean body mass as determined by CT, rather than normalization by predictive equations, may be a useful approach to reduce errors. However, as far as we know, our study is the first to use CT information from ${ }^{18} \mathrm{~F}-\mathrm{NaF}$ PET/ $\mathrm{CT}$ to estimate $\mathrm{SV}$ and to use this volume to normalize the SUV.

In a previous article (26), SV SUV technique was proposed instead of BW SUV. In that article, SUV in normal regions was analyzed in 2 groups of patients with extremes of weight. The results demonstrated that the maximum BW SUV was statistically significantly higher in the subgroup of heavier patients, whereas the maximum SV SUV did not significantly differ in either group of patients. This finding suggested the superiority of normalization by SV since there is no reason for the difference between SUV in heavy and light patients. However, that analysis was performed on a restricted group of 12 patients with extremes of weight and not on 
a larger group of patients with the whole spectrum of weight. Therefore, our study corroborates the finding of this previous study that SV normalization is superior to BW normalization in ${ }^{18} \mathrm{~F}-\mathrm{NaF}$ PET/CT studies, but our study generalizes the results to a large group of patients with a wide range of weights.

Regarding the statistical analyses, we used a 1-tailed test because our initial hypothesis was that the variability in the results for whole-skeleton SV SUV was lower than that for BW SUV and not that SV SUV differed from BW SUV. Therefore, the use of a 1-tailed test should be more adequate in this situation. We also used a nonparametric test for the reason that variability was defined as the absolute difference between one value and the mean of all values (Eq. 3). Therefore, the variabilities are not normally distributed, and it is necessary to use a nonparametric test to perform the statistical analysis. Lastly, because we analyzed paired samples, we used the Wilcoxon signed-rank test, a nonparametric paired-samples test that is equivalent to the parametric paired-samples $t$ test (27).

The reason we used whole-skeleton SUV instead of segmental bone SUV to analyze bone metabolism is that we believe the former, being less susceptible to regional aspects such as mechanical stress, is a more representative measure of the entire skeletal metabolism (28). In addition, the whole-skeleton SUV could be a useful parameter to follow up patients with benign or malignant diffuse bone disease. Therefore, knowing the best normalization method for this parameter could be useful to properly perform wholeskeleton metabolism analysis.

The reason we used ${ }^{18} \mathrm{~F}-\mathrm{NaF}$ PET/CT studies showing normal results instead of pathologic results is that pathologic results would show much more variable uptake, ranging from faint focal uptake in a specific bone region to diffuse and intense skeletal uptake. Such biologic variability could mask the analysis of variability caused by differences in normalization methods.

\section{CONCLUSION}

In patients with normal ${ }^{18} \mathrm{~F}-\mathrm{NaF}$ PET/CT results, $\mathrm{SV} \mathrm{SUV}_{\text {mean }}$ presents lower variability than BW $\mathrm{SUV}_{\text {mean }}$. Therefore, the use of SV normalization seems more precise than normalization by BW to semiquantitatively analyze ${ }^{18} \mathrm{~F}-\mathrm{NaF}$ PET/CT studies.

\section{DISCLOSURE}

No potential conflict of interest relevant to this article was reported.

\section{REFERENCES}

1. Lucignani G, Paganelli G, Bombardieri E. The use of standardized uptake values for assessing FDG uptake with PET in oncology: a clinical perspective. Nucl Med Commun. 2004;25:651-656.

2. Thie JA. Understanding the standardized uptake value, its methods, and implications for usage. J Nucl Med. 2004;45:1431-1434.
3. Brenner W, Vernon C, Muzi M, et al. Comparison of different quantitative approaches to ${ }^{18}$ F-fluoride PET scans. J Nucl Med. 2004;45:1493-1500.

4. Puri T, Blake GM, Frost ML, et al. Comparison of six quantitative methods for the measurement of bone turnover at the hip and lumbar spine using ${ }^{18} \mathrm{~F}$-fluoride PET-CT. Nucl Med Commun. 2012;33:597-606.

5. Cook GJ, Parker C, Chua S, Johnson B, Aksnes AK, Lewington VJ. ${ }^{18}$ F-fluoride PET: changes in uptake as a method to assess response in bone metastases from castrate-resistant prostate cancer patients treated with ${ }^{223}$ Ra-chloride (Alpharadin). EJNMMI Res. 2011;1:4.

6. Doot RK, Muzi M, Peterson LM, et al. Kinetic analysis of ${ }^{18} \mathrm{~F}$-fluoride PET images of breast cancer bone metastases. J Nucl Med. 2010;51:521-527.

7. Zasadny KR, Wahl RL. Standardized uptake values of normal tissues at PET with 2-[fluorine-18]-fluoro-2-deoxy-D-glucose: variations with body weight and a method for correction. Radiology. 1993;189:847-850.

8. Kim CK, Gupta NC, Chandramouli B, Alavi A. Standardized uptake values of FDG: body surface area correction is preferable to body weight correction. J Nucl Med. 1994;35:164-167.

9. Adams MC, Turkington TG, Wilson JM, Wong TZ. A systematic review of the factors affecting accuracy of SUV measurements. AJR. 2010;195:310-320.

10. Wahl RL, Jacene H, Kasamon Y, Lodge MA. From RECIST to PERCIST: evolving considerations for PET response criteria in solid tumors. J Nucl Med. 2009;50(suppl 1):122S-150S.

11. Halsne T, Müller EG, Spiten AE, et al. The effect of new formulas for lean body mass on lean-body-mass-normalized SUV in oncologic ${ }^{18} \mathrm{~F}$-FDG PET/CT. J Nucl Med Technol. 2018;46:253-259.

12. Chan T. Computerized method for automatic evaluation of lean body mass from PET/CT: comparison with predictive equations. J Nucl Med. 2012;53:130-137.

13. Decazes P, Metivier D, Rouquette A, Talbot JN, Kerrou K. A method to improve the semiquantification of ${ }^{18} \mathrm{~F}$-FDG uptake: reliability of the estimated lean body mass using the conventional, low-dose CT from PET/CT. J Nucl Med. 2016;57:753-758.

14. Loening AM, Gambhir SS. AMIDE: a free software tool for multimodality medical image analysis. Mol Imaging. 2003;2:131-137.

15. Grant FD, Fahey FH, Packard AB, Davis RT, Alavi A, Treves ST. Skeletal PET with ${ }^{18}$ F-fluoride: applying new technology to an old tracer. $J$ Nucl Med. 2008;49:68-78.

16. Perkins A, Hilson A, Hall J. Global shortage of medical isotopes threatens nuclear medicine services. BMJ. 2008;337:a1577.

17. Even-Sapir E, Metser U, Flusser G, et al. Assessment of malignant skeletal disease: initial experience with ${ }^{18} \mathrm{~F}$-fluoride PET/CT and comparison between ${ }^{18}$ F-fluoride PET and ${ }^{18} \mathrm{~F}$-fluoride PET/CT. J Nucl Med. 2004;45:272-278.

18. Even-Sapir E, Metser U, Mishani E, Lievshitz G, Lerman H, Leibovitch I. The detection of bone metastases in patients with high-risk prostate cancer: ${ }^{99 \mathrm{~m} T \mathrm{Tc}-\mathrm{MDP}}$ planar bone scintigraphy, single- and multi-field-of-view SPECT, ${ }^{18} \mathrm{~F}$-fluoride PET, and ${ }^{18}$ F-fluoride PET/CT. J Nucl Med. 2006;47:287-297.

19. Krüger S, Buck AK, Mottaghy FM, et al. Detection of bone metastases in patients with lung cancer: ${ }^{99 \mathrm{~m}} \mathrm{Tc}-\mathrm{MDP}$ planar bone scintigraphy, ${ }^{18} \mathrm{~F}$-fluoride PET or ${ }^{18}$ F-FDG PET/CT. Eur J Nucl Med Mol Imaging. 2009;36:1807-1812.

20. Kubota S, Inaba Y, Kobayashi N, et al. Prediction of femoral head collapse in osteonecrosis using ${ }^{18} \mathrm{~F}$-fluoride positron emission tomography. Nucl Med Commun. 2015;36:596-603.

21. Waterval JJ, Vallinga M, Brans B, Winkens B, Stokroos RJ. ${ }^{18}$ F-fluoride PET/CT scan for quantification of bone metabolism in the inner ear in patients with otosclerosis: a pilot study. Clin Nucl Med. 2013;38:677-685.

22. Rohren EM, Etchebehere EC, Araujo JC, et al. Determination of skeletal tumor burden on ${ }^{18} \mathrm{~F}$-fluoride PET/CT. J Nucl Med. 2015;56:1507-1512.

23. Etchebehere EC, Araujo JC, Fox PS, Swanston NM, Macapinlac HA, Rohren EM. Prognostic factors in patients treated with ${ }^{223} \mathrm{Ra}$ : the role of skeletal tumor burden on baseline ${ }^{18} \mathrm{~F}$-fluoride PET/CT in predicting overall survival. J Nucl Med. 2015;56:1177-1184.

24. Hamill JJ, Sunderland JJ, LeBlanc AK, Kojima CJ, Wall J, Martin EB. Evaluation of CT-based lean-body SUV. Med Phys. 2013;40:092504.

25. Kim WH, Kim CG, Kim DW. Comparison of SUVs normalized by lean body mass determined by $\mathrm{CT}$ with those normalized by lean body mass estimated by predictive equations in normal tissues. Nucl Med Mol Imaging. 2012;46:182-188.

26. Carvalho G, Marin JF, Garcez AT, Duarte PS, Sapienza MT, Buchpiguel CA. SUV normalized by skeletal volume on ${ }^{18} \mathrm{~F}$-fluoride PET/CT studies. Clin Nucl Med. 2016;41:529-533.

27. Whitley E, Ball J. Statistics review 6: nonparametric methods. Crit Care. 2002;6: 509-513.

28. Nomura S, Takano-Yamamoto T. Molecular events caused by mechanical stress in bone. Matrix Biol. 2000;19:91-96. 